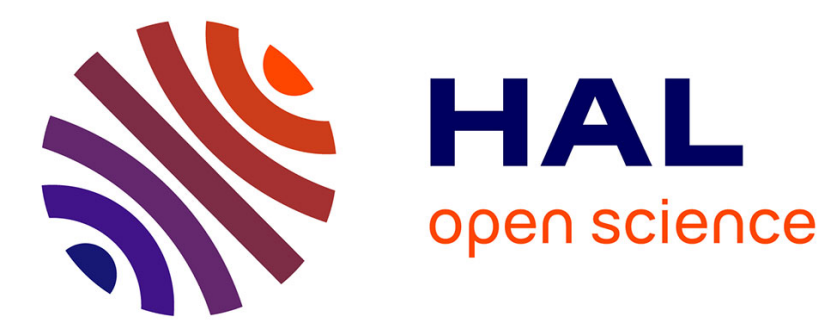

\title{
Beam characterization of a lab bench cold cathode ultra-soft X-ray generator
}

Nabil Ounoughi, Christophe Mavon, Abdelfettah Belafrites, Jean-Emmanuel Groetz, Michel Fromm

\section{- To cite this version:}

Nabil Ounoughi, Christophe Mavon, Abdelfettah Belafrites, Jean-Emmanuel Groetz, Michel Fromm. Beam characterization of a lab bench cold cathode ultra-soft X-ray generator. Nuclear Instruments and Methods in Physics Research Section B: Beam Interactions with Materials and Atoms, 2013, 305, pp.61-66. 10.1016/j.nimb.2013.04.050 . hal-00858423

\section{HAL Id: hal-00858423 https://hal.science/hal-00858423}

Submitted on 5 Sep 2013

HAL is a multi-disciplinary open access archive for the deposit and dissemination of scientific research documents, whether they are published or not. The documents may come from teaching and research institutions in France or abroad, or from public or private research centers.
L'archive ouverte pluridisciplinaire HAL, est destinée au dépôt et à la diffusion de documents scientifiques de niveau recherche, publiés ou non, émanant des établissements d'enseignement et de recherche français ou étrangers, des laboratoires publics ou privés. 


\title{
Beam characterization of a lab bench cold cathode ultra-soft $\mathrm{x}$-ray generator
}

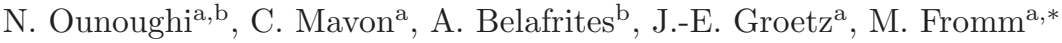 \\ ${ }^{a}$ Laboratoire Chrono-Environnement UMR CNRS 6249, LCPR-AC, Université de Franche-Comté, 16 \\ route de Gray, 25030 Besançon Cedex, France \\ ${ }^{b}$ Laboratoire de Physique des Rayonnements et Applications, Université de Jijel, B.P. 98 Ouled Aissa \\ Jijel 18000 Algérie
}

\begin{abstract}
The aim of this work is to characterize the Ultra Soft X-ray (USX, $1.5 \mathrm{keV}, \mathrm{Al} \mathrm{K} \alpha$ ) photon beam of a customized lab bench cold cathode generator. Within this generator, the electron beam is slowed down in a thin aluminium foil $(16 \mu \mathrm{m})$ supported by an easily exchangeable anode. It is shown that the thickness of the foil and the anode configuration determine the spatial distribution and the fluence rate of the photon beam, whereas accelerating voltage determines both fluence rate and energy spectrum feature. It is shown also that under specific operation parameters (i.e. accelerating voltage), a Gaussian energy distribution of the beam can be generated which is centred on the energy of the Al K $\alpha$ line $(1.5 \mathrm{keV})$. Dosimetric films of GAFCHROMIC@HD-810 were used to estimate the photon fluence rate distribution of the beam. Its variation, when the generator acts as a monoenergetic source, was characterized with the two different configurations of the anode assembly. Finally, it is verified that one of both anode assemblies acts as a simple point-source.
\end{abstract}

Keywords: Ultra-soft X-rays (USX), USX Cold cathode generator, Gafchromic dosimetry, Aluminium $\mathrm{K} \alpha$ line.

\section{Introduction}

Due to their nanometer-scaled spatial energy depositions, comparable to the dimen3 sions of critical structures within the cell, Ultrasoft X-rays (USX: photon energy $<5 \mathrm{keV}$ ) 4 provide a unique tool in the study of the mechanisms of radiobiological action (inactivation, mutation, chromosome aberrations and cell transformation) [1]. USX, however, pose significant problems in dosimetry and experimental design, due to their considerable attenuation in matter $[2,3]$.

Putting aside the synchrotron radiation sources, USX beams can be produced at the laboratory level by means of commercial or tailor-made X-ray sources. If commercially available X-ray sources are generally based on hot cathode tubes, cold-cathode discharge

\footnotetext{
* Corresponding author

Email address: michel.fromm@univ-fcomte.fr (M. Fromm)

Preprint submitted to Nucl. Instrum. Meth. B
} 
tubes are the most frequently used sources of USX for radiobiological studies [4-6].The main advantages of those tubes are their good spectral purity due to self-absorption in the target, simplicity in design and operation as well as minimal maintenance requirements. In addition such sources do not operate in high vacuum, a primary vacuum is sufficient to create the discharge. However, cold-cathode tubes are limited to targets available under the form of very thin self-supporting films [1].

Using such sources to expose biological samples to USX and/or secondary low-energy photoelectrons $[4,5]$ requires a whole characterization of the photon beam with respect to the tubes operating parameters and geometry.

The main objective of this study is to investigate the USX beam emission from a cold cathode gas discharge generator with a transmission anode (thin foil of aluminium). The energy spectrum was measured in dependence of the operating parameters of the generator as well as for two different configurations of the anode assembly configuration. The USX photon spatial distribution of fluence rates were determined by using $2 \mathrm{D}$ radiochromic (gafchromic) films with an appropriate calibration.

\section{Materials and methods}

\subsection{Irradiation}

\subsubsection{Cold cathode X-ray generator}

The conception of the generator is based on a design first proposed by Solomon and Baun in the early sixties [7] and revisited in the eighties by Hoshi et al [2]. Briefly described, the USX source is composed of a metallic (brass) chamber containing the electrodes, maintained at a low pressure $\left(\sim 5 \times 10^{-2}\right.$ mbar, i.e. $\left.5 \mathrm{~Pa}\right)$ of dehydrated air using a mechanical pump. In this device, the anode foil (target), in which accelerated electrons are slowed down to produce USX $(\mathrm{Al} \mathrm{K} \alpha)$, constitutes the window that separates the chamber from the outer part of the generator at atmospheric pressure. The cold cathode made up of aluminium is machined so that it has a concave shape (Fig. 1). Insulated from the chamber by a surrounding ceramic cylinder, the cathode electrical contact is put at a negative potential, the chamber and the target are at the ground. When high voltage is applied, under given internal pressure conditions, an electric discharge appears between the electrodes and the electric current can be stabilized. A Townsend discharge is sustained by multiplication of electron flow through ion impact on the cathode when a critical value of the electric field strength is reached that depends on the gas density. Electrons interact with the atoms of the aluminium foil giving rise to the emission of characteristic $\mathrm{K} \alpha(1.5 \mathrm{keV})$ USX accompanied by the emission of bremsstrahlung radiation. These radiations are transmitted through the foil and emerge outside the tube. Concave metal cathodes are generally used to focus the electrons on a small area of the anode target in order to increase the production of X-rays. Special efforts were made in the design of the generator in order to be easily dismantled and upkeep (cleaning the chamber).

In the present study, two different anodes were used, a first one where the aluminium foil is supported by a grid and a second one where the aluminium foil is set down on a metallic support through which a $8 \mathrm{~mm}$ diameter hole is drilled (so-called flat washer, see Figure 2 for more details). 


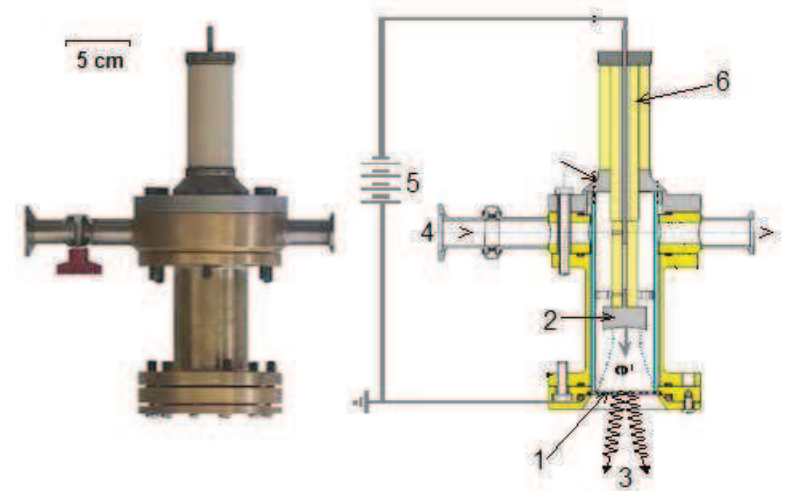

Figure 1: A photograph and a schematic cross-sectional view of the USX cold-cathode generator: (1) aluminium foil (see Figure 2 for more details), (2) Concave aluminium cathode, (3) USX in the outer atmosphere, (4) to vacuum gauge, (5) high electric voltage supply, (6) ceramic support insulation.

\subsection{2. $\gamma$ ray irradiation}

${ }^{60} \mathrm{Co}(1173.2$ and $1332.5 \mathrm{keV})$ irradiations were performed at the Laboratoire National Henri Becquerel (LNHB, the French National Reference Laboratory for Metrology of Ionizing Radiation) of the French Atomic Agency (CEA) in Saclay, France. This laboratory is the national reference laboratory for ${ }^{60} \mathrm{Co}$ Kerma in air, especially for radiotherapy.

\subsection{Gafchromic dosimetry}

The commercially available dosimetric films (HD-810, ISP Technologies Inc., Wayne, NJ), that are originally transparent, become bluer proportionally to the energy deposited by ionizing radiation. The film is composed of three layers: a gelatin surface layer $(0.75$ $\left.\mu \mathrm{m}, \rho=1.08 \mathrm{~g} . \mathrm{cm}^{-3}\right)$, an active layer $\mathrm{AL}\left(6.5 \mu \mathrm{m}, \rho=1.2 \mathrm{~g} . \mathrm{cm}^{-3}\right)$ and a transparent polyester support layer $\left(97 \mu \mathrm{m}, \rho=1.35 \mathrm{~g} . \mathrm{cm}^{-3}\right)$. Absorbance in the visible spectrum for different absorbed doses in HD-810 was recorded using a Varian, Cary 100 Scan, UVvisible spectrophotometer. Films were scanned in color at $300 \times 300 \mathrm{dpi}$, using a document scanner (Canon PCL6 Driver Generic), and then processed by the image processing software (Image $\mathrm{J}$ ). Image $\mathrm{J}$ is a public domain, Java-based image processing program developed at the National Institutes of Health of the USA (http://rsbweb.nih.gov/ij/).

\subsection{X-ray spectra measurements}

X-ray spectra have been measured using a semiconductor type detector AMTEK, Model XR-100CR (Si-PIN photodiode). XR-100CR is a high performance X-ray detector mounted on a thermo-electric cooler (Peltier type) together with the input FET to the pre-amplifier. These components are kept at $-55^{\circ} \mathrm{C}$ and are enclosed in a hermetic package with a Beryllium window [8]. It can be operated in air or in vacuum with a $149 \mathrm{eV} \mathrm{FWHM}$ resolution at $5.9 \mathrm{keV}$. At high USX flux (i.e. a short source-detector distance) pulse pileup arises and radiation damage to the detector can occur. Therefore, the spectra where measured only at distances greater than $5 \mathrm{~mm}$. 

by taking into account both absorption and mechanical resistance.

\begin{tabular}{ccc}
\hline Incident energy $(\mathrm{keV})$ & Exp. range $(\mu \mathrm{m})$ & Kanaya-Okayama Range $(\mu \mathrm{m})$ \\
\hline 2.5 & 0.21 & 0.13 \\
5 & 0.48 & 0.41 \\
10 & 1.11 & 1.31 \\
\hline
\end{tabular}

Table 1: Kanaya-Okayama electron maximum penetration range and experimental data in aluminium from Ref.[9]

\subsection{Anode configuration}

During operation of the X-ray tube, the inner pressure has an order of magnitude of $10^{-2}$ mbar. Optimizing the thickness of the aluminium foil used depends on two separate parameters: auto-absorption of USX and mechanical resistance owing to the fact that it has to resist to the pressure difference.

The maximum penetration range of electrons in aluminium can be estimated by means of Kanaya and Okayama semi-empirical expression [9]. Table (1) shows that for electrons at $5 \mathrm{keV}$ the maximum range in aluminium does not exceed $0.5 \mu \mathrm{m}$, any supplementary thickness added will therefore act as a filter (absorber), whose size must be minimized

Two different configurations of the anode assembly were used:

- the first one, where the $\mathrm{Al}$ foil target serves also as vacuum window; it is supported on a copper grid that has a $45 \%$ transparency ratio (holes diameter $=0.25 \mathrm{~mm}$, Fig. 2a);

- the second one, where the $\mathrm{Al}$ foil is mechanically maintained using a flat washer with an aperture diameter of $8 \mathrm{~mm}$ (Fig. 2b).

A $16 \mu \mathrm{m}$ thick foil was used for the aluminium target in order to ensure its mechanical resistance. Based on Atomic Data and Nuclear Data Tables [10], Fig. 3 shows the photon

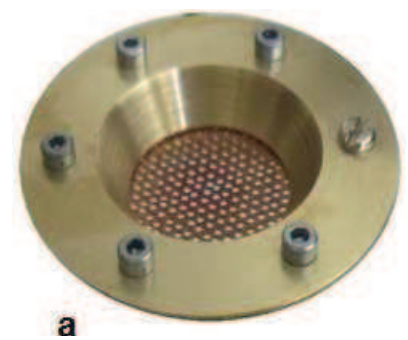

(a) the aluminium foil is supported by a copper grid

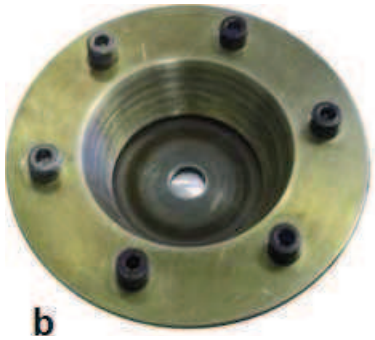

(b) the foil is partially autosupported and mechanically maintained using a flat washer with an aperture of $8 \mathrm{~mm}$ diameter.

Figure 2: Anode assembly configurations.

\section{Results and discussion}


transmission of an $\mathrm{Al}$ foil with thickness at $16 \mu \mathrm{m}$, for X-ray energies below $6 \mathrm{keV}$, which plays the role of a filter. For energies greater than $2.5 \mathrm{keV}$, transmission increases with increasing photon energy. Below $2.5 \mathrm{keV}$, only a weak transmission is observed and it peaks at $1.5 \mathrm{keV}$, the value of the $\mathrm{Al} \mathrm{K} \alpha$ line. This shows that with a thickness at $16 \mu \mathrm{m}$, if, on the one hand the transmission ratio is lowered, on the other hand, when operating with an accelerating voltage less than $2 \mathrm{keV}$, the transmitted energy is essentially due to the $\mathrm{Al} \mathrm{K \alpha}$ line.

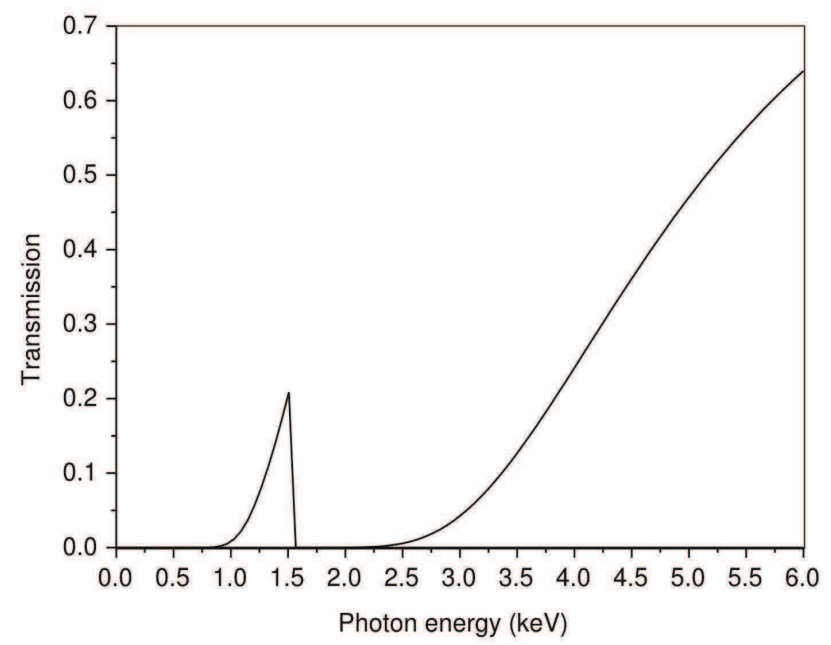

Figure 3: Transmission of $15.5 \mu \mathrm{m}$ thick Al foil (corresponding to $16 \mu \mathrm{m}$ thick with an electron full range set at $0.5 \mu \mathrm{m})$ for energy below $6 \mathrm{keV}[10]$

\subsection{Photon energy spectra}

Fig. 4 shows the measured photon energy spectra of the USX beam, at accelerating voltages ranging from 2 to $3 \mathrm{kV}$, as measured using a semiconductor detector (Si-PIN photodiode). The measurement is performed at $5 \mathrm{~cm}$ from the aluminium foil and at very low tube current as it is recommended to operate the detector at low photon fluence rate $[8]$.

At $2.5 \mathrm{kV}$ and at $5 \mathrm{~cm}$ from the aluminium target foil the bremsstrahlung emission becomes visible in addition to the $\mathrm{Al} \mathrm{K} \alpha$ line, in this case bremsstrahlung is about $15 \%$ of the total count (Fig. 4). The percentage of bremsstrahlung contribution at different distances below $5 \mathrm{~cm}$ decreases because the air attenuation coefficient of photons at energy $1.5 \mathrm{keV}$ is greater than for photons at higher energies. The mass attenuation coefficients of air at photon energy $E=1.5,2$ and $3 \mathrm{keV}$ are respectively $1.19 \times 10^{3}$, $5.28 \times 10^{2}$ and $1.63 \times 10^{2} \mathrm{~cm}^{2} \cdot \mathrm{g}^{-1}[16]$.

Remarkably, at $2 \mathrm{kV}$ operation, bremsstrahlung emission is negligible and the beam can be considered as mono-energetic; it is essentially composed of $\mathrm{Al} \mathrm{K} \alpha$ photons. It should be noticed that the more the accelerating voltage increases, the more pulse pill-up counts appear at energies greater than the equivalent voltage. This latter phenomenon is indicated in Fig. 4 for the most obvious case, i.e. at $3 \mathrm{kV}$. 


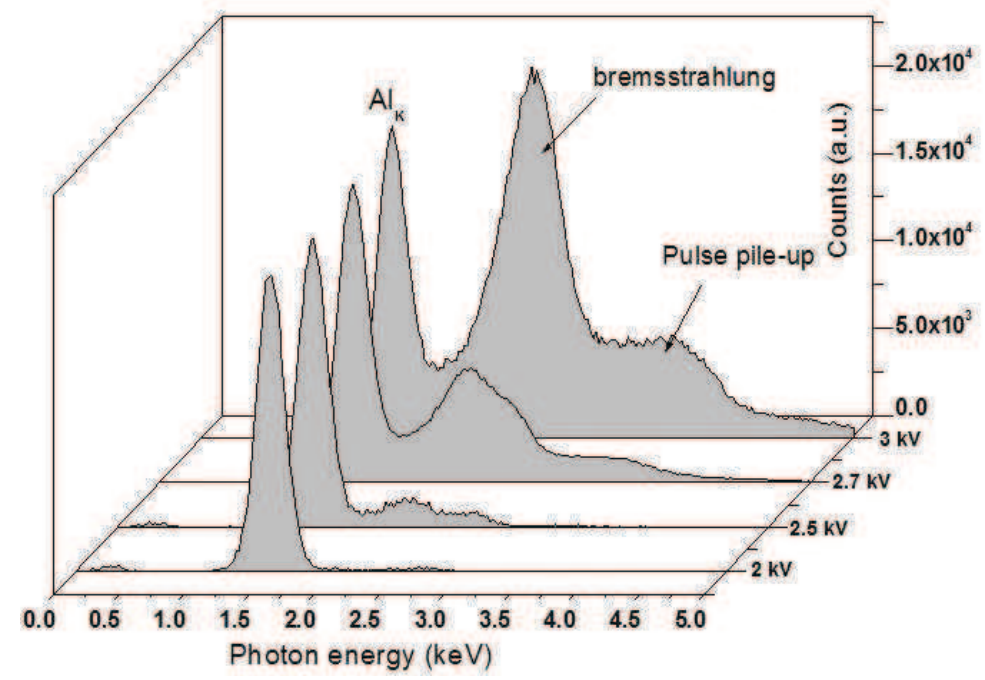

Figure 4: Experimental USX energy spectrum in air measured at $5 \mathrm{~cm}$ from aluminium foil at different accelerating voltages.

\subsection{Gafchromic film calibration and uncertainties}

The study of the spatial distribution of fluence rate for the USX beam is estimated using two-dimensional gafchromic films, often used for 2D dose measurement in the range 10-400 Gy [11].

The dosimetry with Gafchromic films is based on the measurement of absorbance (optical density, OD) variation. To convert the absolute response, it is necessary to determine the calibration curve (dose $=\mathrm{f}(\mathrm{OD})$ ). ODs can be determined either by UVVis spectrometry or using a document scanner [12-14]. In the present study, six HD-810 films $(2 \times 2 \mathrm{~cm})$ were irradiated at various ${ }^{60} \mathrm{Co} \gamma$-ray $(1173.2$ and $1332.5 \mathrm{keV})$ doses in air, under electronic equilibrium conditions: 10.20, 19.76, 40.08, 60.00, 100.02, 200.30 Gy.

Two films that were not irradiated, but suffered the same environmental effects also were used as control. Absorbance of HD-810 films in the visible spectrum for different air kermas was recorded using a UV-visible spectrophotometer. The spectra show absorbance peaks in the red region (Fig. 5).

Films were scanned in color at $300 \times 300 \mathrm{dpi}$, using a document scanner (Canon PCL6 Driver Generic), and then processed by the image processing software (Image J). According to the results shown in Fig. 5, only the red level was extracted from the whole RGB image and analysed. The variation in optical density (OD) caused by irradiation is calculated using the standard equation:

$$
\mathrm{OD}=\log \left(\frac{I_{C}}{I_{M}}\right)
$$

where $I_{C}$ and $I_{M}$ are respectively the grey levels determined from the region of interest selected from control and irradiated films, with $\sigma_{I_{C}}$ and $\sigma_{I_{M}}$ their corresponding uncertainties. The uncertainty on OD measurements, assuming that there is no correlation 
between $I_{C}$ and $I_{M}$, is calculated using:

$$
\sigma=\frac{1}{\ln 10} \sqrt{\frac{\sigma_{I_{C}}^{2}}{I_{C}^{2}}-\frac{\sigma_{I_{M}}^{2}}{I_{M}^{2}}}
$$

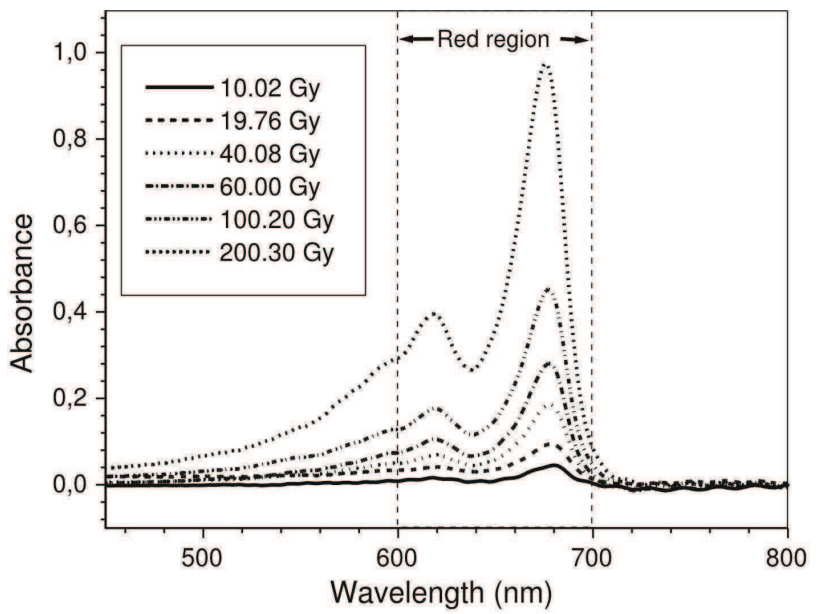

Figure 5: Absorbance spectra as measured on HD-810 films in the visible region after exposure at various $\gamma$-ray air kermas (see caption)

The relation linking dose in air to OD is given by the linear fit of the curve presented in Fig. 6, whose slope is denoted $\alpha$ :

$$
{ }^{\gamma} D_{\text {air }}=\left(\alpha \pm \sigma_{\alpha}\right) \times \mathrm{OD}
$$

Assuming that the uncertainty on measured dose in air is only dependant on measurement uncertainty $\sigma_{\mathrm{OD}}$ and fitting parameters, we can write:

$$
\sigma_{\gamma} D_{\text {air }}=\sqrt{\alpha^{2} \times \sigma_{\mathrm{OD}}^{2}+\mathrm{OD}^{2} \times \sigma_{\alpha}^{2}}
$$

The calibration curve shown in Fig. 6 follows a linear relationship with dose in air within the range 10-200 Gy. Interestingly the relative uncertainty drops down to values that are less than $5 \%$ for doses in air greater than $50 \mathrm{~Gy}$.

\subsection{Photon fluence rates}

As mentioned by ref [14], the formation of the blue polymer product in the HD-810 films is assumed to be characterized by an average energy deposition independent of radiation quality [15]. Thus, the mean absorbed dose of USX to the active layer (AL) of HD-810 film; ${ }^{\mathrm{USX}} D_{m}$ can be derived from equations (4) and (5) [4]:

$$
\begin{aligned}
{ }^{\mathrm{USX}} D_{m} & ={ }^{\gamma} D_{\mathrm{AL}} \\
& =\frac{\gamma\left(\mu_{\mathrm{en}} / \rho\right)_{\mathrm{AL}}}{\gamma\left(\mu_{\mathrm{en}} / \rho\right)_{\text {air }}} \times{ }^{\gamma} D_{\text {air }} \\
& =\frac{1.09 \times \gamma D_{\text {air }}}{7}
\end{aligned}
$$


Figure 6: Calibration curve reference dose in air versus OD. The inset shows the variation of relative uncertainties (\%) with measured dose. Note that for doses in air above 50 Gy the relative uncertainty will not exceed $5 \%$.

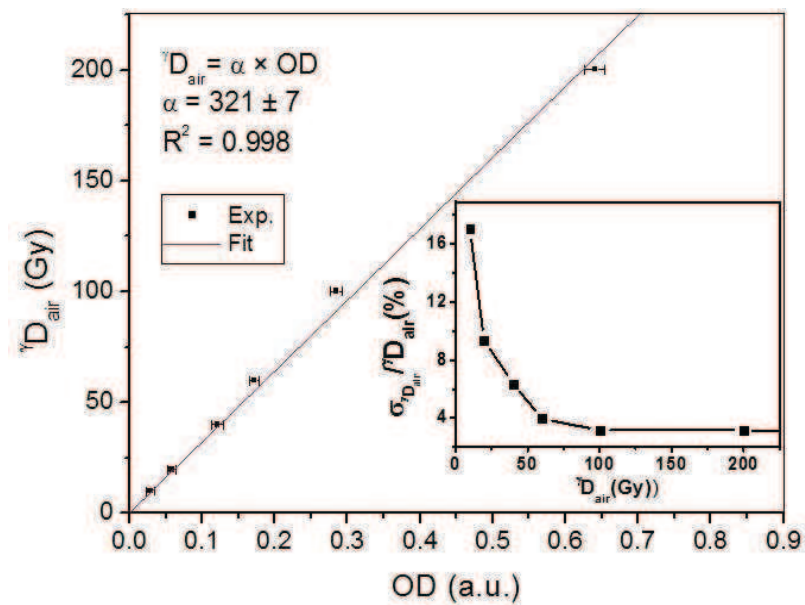

where the $\mu_{\mathrm{en}} / \rho$ are the mass-energy absorption coefficients, their values for AL and air are respectively $2.91 \times 10^{-2} \mathrm{~cm}^{2} \cdot \mathrm{g}^{-1}[14]$ and $2.666 \times 10^{-2} \mathrm{~cm}^{2} \cdot \mathrm{g}^{-1}[16]$. The surface dose rate in the active layer can be calculated using [17]:

$$
{ }^{\operatorname{USx}} \dot{D}_{S}={ }^{\operatorname{USx}} \dot{D}_{m} \frac{\left(\frac{\mu}{\rho}\right) \rho . d}{1-\exp \left[-\left(\frac{\mu}{\rho}\right) \rho . d\right]}
$$

where $\mu / \rho=809 \mathrm{~cm}^{2} \cdot \mathrm{g}^{-1}$ is the mass attenuation coefficient of AL, $\rho$ and $d$ are respectively the density and the thickness of AL. The photon fluence rate $\dot{\Phi}_{\mathrm{AL}}$ at the incident surface of the active layer can be calculated using:

$$
\dot{\Phi}_{\mathrm{AL}}=C \times \frac{\mathrm{USX}_{\dot{D}_{S}}}{\left(\mu_{\mathrm{en}} / \rho\right)_{\mathrm{AL}} \times E}
$$

where $C$ is the conversion coefficient of $6.24 \times 10^{17} \mathrm{eV} \cdot \mathrm{g}^{-1} \cdot \mathrm{Gy}^{-1}, E$ is the photon energy (1.5 keV for $\mathrm{Al} \mathrm{K \alpha}$ X-rays, see 3.1 Photon energy spectra). Finally, the photon fluence rate at the surface of HD-810 film can be estimated by computing relation (8), taking into account the attenuation in the surface layer by means of the mass attenuation coefficient at $1.5 \mathrm{keV}$ equal to $9.95 \times 10^{2} \mathrm{~cm}^{2} \cdot \mathrm{g}^{-1}$ :

$$
\begin{aligned}
\dot{\Phi}_{S} & =7.5 \times 10^{11} \times{ }^{\mathrm{USX}} \dot{D}_{m} \\
& =2.57 \times 10^{14} \times \frac{\mathrm{OD}}{t}
\end{aligned}
$$




\subsection{Spatial photon fluence rate distributions}

When USX photon beams are applied to biological samples, it is necessary to know

where $\mu / \rho$ is the mass attenuation coefficient in air at the considered energy.

Figure 7: Radial profile of USX photon fluence rate distributions for the two anode configurations (generator parameters: $2.4 \mathrm{kV}, 3 \mathrm{~mA}, 6 \times 10^{-2}$ mbar). Measurements are performed at $13 \mathrm{~mm}$ from the aluminium target. The color inset on the upper-right part of the figure is the radial fluence rate distribution determined by means of image analysis of the dosimetric films when the flat-washer was used as an anode configuration.

\subsection{Estimation of the beam dimensions}

When using a mechanically maintained aluminium foil supported by a flat washer, due to the pressure difference between inner and outer parts of the chamber, the aluminum foil takes the shape of a concave lens. In such a case, the generator acts like a quasi-point source. For a mono-energetic photon point-source in air along the beam axis, the photon fluence rate at two distances $x$ and $y(x<y)$ from the source can therefore be expressed as a combination of the beam divergence and its attenuation in air:

$$
\dot{\Phi}_{y}=\dot{\Phi}_{x} \frac{x^{2}}{y^{2}} \times \exp \left[\left(\frac{\mu}{\rho}\right) \times \rho(x-y)\right]
$$


It is assumed that the USX source under $2 \mathrm{kV}$ accelerating voltage is a point source located at $2 \mathrm{~mm}$ into the vacuum chamber from the aluminium foil. The photon fluence rates at different distances from the point-source were thus measured using the Gafchromic (HD-810) films by applying the methodology described above.

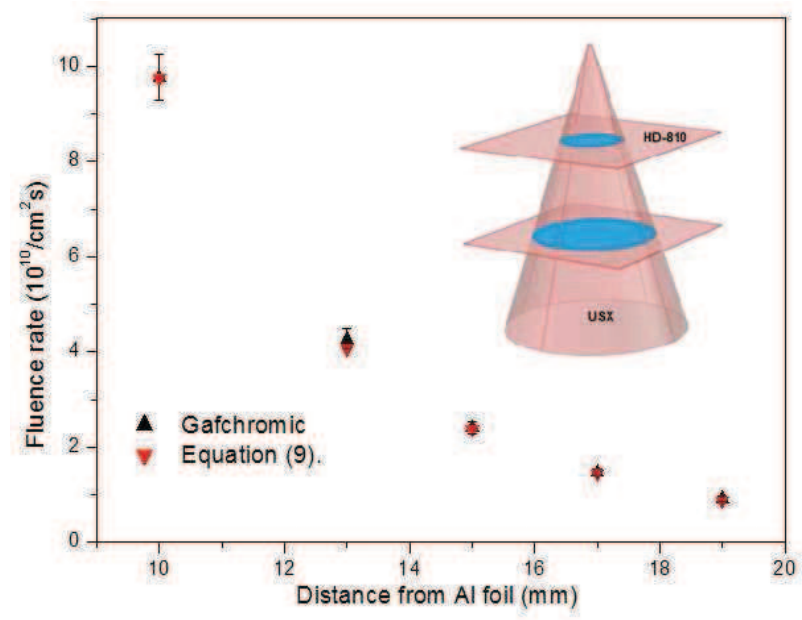

Figure 8: Measured photon fluence rate along the beam axis at different distances from source compared to the calculated values (9). The experimental value at $10 \mathrm{~mm}$ serves as an input data in (9).

Distances to the aluminium foil were fixed using a linear roller screw driven positioning stage with a $10 \mu \mathrm{m}$ precision. Values in the close vicinity to the maximum of the Gaussian fluence distributions (Fig. 7) have been used to computing Eq.(9). A rather very satisfactory accordance between calculated and measured data is found which confirms that the beam originates from a point-source. This result constitutes substantial time-savings for future experiments where the photon fluence rates have to be determined at various distances, when using the target configuration based on the flat washer.

\section{Conclusion}

In this study, we have characterized the beam of a tailor-made lab table cold-cathode USX generator equipped with two different aluminum foil anode assembly configurations. A first preliminary estimation based on Atomic and Nuclear Data Tables has provided evidence for preferential transmission of the $\mathrm{K} \alpha$ line through a $16 \mu \mathrm{m}$ thick aluminium target when the USX photons have energies less than $2 \mathrm{keV}$. This has been confirmed experimentally by spectrometric measurements based on a Si-PIN X-ray detector; at 2 $\mathrm{kV}$ acceleration voltage; the experimental spectrum is quasi-monoenergetic (Gaussian distribution), centred on the $\mathrm{Al} \mathrm{K} \alpha$ line, i.e. $1.5 \mathrm{keV}$. The use of Gafchromic dosimetric films enabled the fluence rate distributions to be estimated using ${ }^{60} \mathrm{Co}$ air Kerma reference calibration and transfert to both anode assemblies used via dosimetric film irradiation. It was found that the anode assembly made up of a flat washer (with a $8 \mathrm{~mm}$ hole diameter) produces a fluence rate twice of that of the same aluminium foil supported by a grid with a $45 \%$ transparency ratio. A three-dimensional representation of the 
radial fluence rate distribution of the beam was deduced from image analysis of the regions of interest on the dosimetric films. The expected behaviour of the so-called verified by applying both quadratic and exponential properties (Eq. 9), particular to point-sources. Intended to be used for radiobiology experiments, this USX generator has beam characteristics comparable to those generally used in this area of research. Studies are currently under investigation to designing a free-air ionization chamber aimed at evaluating the USX photon fluence rate (by measuring air kerma of the monoenergetic photon beam) in routine work.

\section{References}

[1] M. A. Hill, The use of CVD diamond to produce carbon K ultrasoft x-rays, Phys. Med. Biol. 48 (2003) 223-230.

[2] M. Hoshi, D.T. Goodhead, D. J. Brenner, D. A. Bances, J. J. Chmielewski, M. A. Paciotti, J. N. Bradbury, Dosimetry comparison and characterisation of an Al K ultrasoft x-ray beam from an MRC cold-cathode source Phys. Med. Biol. 30(10) (1985) 1029-1041.

[3] S. Endo, M. Hoshi, J. Takada, T. Takatsuji, Y. Ejima, S. Saigusa, A. Tachibana, M. Sasaki, Development, beam characterization and chromosomal effectiveness of X-rays of RBC characteristic X-ray generator J. Radiat. Res. 47 (2006) 103-112.

[4] Z. Cai, P. Cloutier, D. Hunting, L. Sanche, Enhanced DNA damage induced by secondary electron emission from a tantalum surface exposed to soft X rays, Rad. Reas. 165 (2006) 365-371.

[5] E. Brun, P. Cloutier, C. Sicard-Roselli, M. Fromm, L. Sanche, Damage induced to DNA by lowenergy (0-30 eV) electrons under vacuum and atmospheric conditions, J. Phys. Chem. B 113 (2009)10008-10013.

[6] D.T. Goodhead, J. Thacker, Inactivation and mutation of cultured mammalian cells by aluminium characteristic ultrasoft X-rays, Int. J. Radiat. Biol. 316 (1977) 541-559.

[7] J. S. Solomon and W. L. Baun. A cold cathode soft X-ray source. Rev. Sci. Instrum. 40 (1969) 1458-1461.

[8] T. J. Pantazis, A. Pantazis and R. Huber. The historical development of the thermoelectrically cooled X-ray detector and its impact on the portable and hand-held XRF industries. X-Ray Spectrometry 392 (2010) 90-97.

[9] M. Dapor, Monte Carlo simulation of backscattered electrons and energy from thick targets and surface films, Phys. Rev. B 46 (1992) 618-625.

[10] B. L. Henke, E. M. Gullikson, J. C. Davis, X-ray interactions: photo-absorption, scattering, transmission and reflection at $\mathrm{E}=50-30000 \mathrm{eV}, \mathrm{Z}=1-92$, Atomic Data and Nuclear Data Tables 54 (2) (1993) 181-342.

[11] ISP, Gafchromic HD-810 Radiochromic Dosimetry Film and D-200 Pre-Formatted Dosimeters for High-Energy Photons, Configuration, Specifications and Performance Data (Wayne, NJ: International Specialty Products) 2002. Online at http://www.ispcorp.com/products/dosimetry/products/810 200/conspefo.pdf

[12] M.Bazioglu, J. Kalef-Ezra, Dosimetry with radiochromic films: a document scanner technique, neutron response, applications, Appl. Radiat. Isot. 553 (2001) 339-345.

[13] S. Devic, J Seuntjens, E. Sham, E. B. Podgorsak, Precise radiochromic film dosimetry using a flat-bed document scanner Med. Phys. 327 (2005) 2245-2253.

[14] Z. Cai, X. Pan, D. Hunting, P. Cloutier, R. Lemay, L. Sanche, Dosimetry of ultrasoft x-rays (1.5 $\mathrm{keV}$ AlK $\alpha$ ) using radiochromatic films and colour scanners, Phys. Med. Biol. 48 (2003) 4111-4124.

[15] W. V. Prestwich, R. J. Murphy, Calculated dose response of Gafchromic MD55 film for ${ }^{103} \mathrm{Pd}$ and ${ }^{125}$ I relative to ${ }^{60} \mathrm{Co}$, Radiat. Meas. 32 (2000) 173-179.

[16] J. H. Hubbell, S.M. Seltzer, Tables of x-ray mass attenuation coefficients and mass energy-absorption coefficients from $1 \mathrm{keV}$ to $20 \mathrm{MeV}$ for elements $\mathrm{Z}=1$ to 92 and 48 additional substances of dosimetric interest, (Gaithersburg, MD: National Institute of Standards and Technology) NIST (1996) report 5632 .

[17] J. Fulford, P. Bonner, D.T. Goodhead, M. A. Hill, P. ONeill, Experimental determination of the dependence of $\mathrm{OH}$ radical yield on photon energy: a comparison with theoretical simulations, J. Phys. Chem. A 103 (1999) 11345-11349. 